\title{
Experimental comparison and visualization of in-tube continuous and pulsating flow boiling
}

Kærn, Martin Ryhl; Markussen, Wiebke Brix; Meyer, Knud Erik; Elmegaard, Brian; Palm, Björn

Published in:

International Journal of Heat and Mass Transfer

Link to article, DOI:

10.1016/j.jheatmasstransfer.2018.04.060

Publication date:

2018

Document Version

Peer reviewed version

Link back to DTU Orbit

Citation (APA):

Kærn, M. R., Markussen, W. B., Meyer, K. E., Elmegaard, B., \& Palm, B. (2018). Experimental comparison and visualization of in-tube continuous and pulsating flow boiling. International Journal of Heat and Mass Transfer, 125, 229-242. https://doi.org/10.1016/j.jijheatmasstransfer.2018.04.060

\section{General rights}

Copyright and moral rights for the publications made accessible in the public portal are retained by the authors and/or other copyright owners and it is a condition of accessing publications that users recognise and abide by the legal requirements associated with these rights.

- Users may download and print one copy of any publication from the public portal for the purpose of private study or research.

- You may not further distribute the material or use it for any profit-making activity or commercial gain

- You may freely distribute the URL identifying the publication in the public portal 


\title{
Experimental comparison and visualization of in-tube continuous and pulsating flow boiling
}

\author{
Martin Ryhl Kærn, ${ }^{\mathrm{a}, *}$ Wiebke Brix Markussen ${ }^{\mathrm{a}}$, Knud Erik Meyer ${ }^{\mathrm{a}}$, Brian Elmegaard ${ }^{\mathrm{a}}$, Björn \\ Palm ${ }^{\mathrm{b}}$ \\ ${ }^{a}$ Department of Mechanical Engineering, Technical University of Denmark, Nils Koppels Allé Bygn. 403, DK-2800 \\ Kgs. Lyngby, Denmark \\ ${ }^{b}$ Department of Energy Technology, Royal Institute of Technology, Brinellvägen 68, S-100 44 Stockholm, Sweden
}

\begin{abstract}
This experimental study investigated the application of fluid flow pulsations for in-tube flow boiling heat transfer enhancement in an $8 \mathrm{~mm}$ smooth round tube made of copper. The fluid flow pulsations were introduced by a flow modulating expansion device and were compared with continuous flow generated by a stepper-motor expansion valve in terms of the time-averaged heat transfer coefficient. The cycle time ranged from $1 \mathrm{~s}$ to $7 \mathrm{~s}$ for the pulsations, the time-averaged refrigerant mass flux ranged from $50 \mathrm{~kg} \mathrm{~m}^{-2} \mathrm{~s}^{-1}$ to $194 \mathrm{~kg} \mathrm{~m}^{-2} \mathrm{~s}^{-1}$ and the time-averaged heat flux ranged from $1.1 \mathrm{~kW} \mathrm{~m}^{-2}$ to $30.6 \mathrm{~kW} \mathrm{~m}^{-2}$. The time-averaged heat transfer coefficients were reduced from transient measurements immediately downstream of the expansion valves with $2 \mathrm{~K}$ and $20 \mathrm{~K}$ subcooling upstream, resulting in inlet vapor qualities at 0.05 and 0.18 , respectively, and covered the saturated flow boiling range up to the dry-out inception. Averaged results of the considered range of vapor qualities, refrigerant mass flux and heat flux showed that the pulsations at low cycle time $(1 \mathrm{~s})$ improved the time-averaged heat transfer coefficients by $5.6 \%$ and $2.2 \%$ for the low and high subcooling, respectively. However, the pulsations at high cycle time $(7 \mathrm{~s})$ reduced the time-averaged heat transfer coefficients by $1.8 \%$ and $2.3 \%$ for the low and high subcooling, respectively, due to significant dry-out when the flow-modulating expansion valve was closed. Furthermore, the flow pulsations were visualized by high-speed camera to assist in understanding the time-periodic flow regimes and the effect they had on the heat transfer performance.

Keywords: flow boiling, flow pulsation, heat transfer enhancement, visualization, flow regime
\end{abstract}




\section{Introduction}

High heat exchanger performance is crucial to comply with efficiency standards with low cost and environmental impact in various applications such as heat pumps, refrigeration and airconditioning. In a recent paper [1], we compared in-tube continuous and pulsating flow boiling heat transfer experimentally at low vapor qualities, in order to demonstrate possible heat transfer enhancement by introducing flow pulsations. The experimental setup was designed to mimic a refrigeration, air-conditioning or heat pump system with $\mathrm{R} 134 \mathrm{a}$ evaporating at $5{ }^{\circ} \mathrm{C}$ and condensing at $32{ }^{\circ} \mathrm{C}$. Time-averaged heat transfer coefficients were obtained immediately after the expansion valve with $2 \mathrm{~K}$ subcooling upsteam. The pulsations were introduced by a pulsed flow expansion device and compared with continuous flow from a stepper-motor expansion valve. The cycle time ranged from $1 \mathrm{~s}$ to $9 \mathrm{~s}$ for the flow pulsations. We presented first results, derived from a prototype evaporator test section ( $8 \mathrm{~mm}$ smooth round tube made of copper), that indicated a small heat transfer enhancement $(3.2 \%)$ at the lowest cycle times ( $1 \mathrm{~s}$ to $2 \mathrm{~s})$, but also a small penalty at high cycle times and high heat flux due to significant dry-out when the pulsating flow valve was closed. The current paper serves to provide a better foundation for the comparison of continuous and pulsating flow boiling heat transfer. Some important points not addressed in the recent paper, but included in the current paper are: (1) the results cover the whole quality range up to the point of dry-out inception for the continuous flow (and a similar time-averaged quality for the pulsating flow), (2) the results include the effect of larger subcooling (20 K) and thus lower inlet vapor quality, (3) the test sections were improved with four wall temperature measurements circumferentially instead of only two in the recent paper (considered to be enough for the first experimental campaign), (4) since the inlet vapor quality was fixed due to the same boundary condition before the exchangeable expansion valves, the change in quality was interdependent with the change in heat flux. With several test sections, these important variables are no longer correlated or dependent in the data set.

Pulsating flow boiling (or fluid pulsation/vibration) has received little attention in the literature for boiling and condensation enhancement $[2,3]$. It is in fact difficult to find independent studies

${ }^{*}$ Corresponding author. Tel.: +45 4525 4121; fax: +45 45935215.

Email address: pmak@mek.dtu.dk (Martin Ryhl Kærn) 
concerning the same evaporator or condenser type, actuator, and operation conditions, e.g. pulsation frequencies. The reported results are also conflicting, showing that the performance improves, diminish, or result in no appreciable effect. Some earlier findings involving pulsating flow boiling or condensation are summarized in the following, a deeper description of the studies are provided in Kærn et al. [1] and are not repeated herein.

Antonenko et al. [4] studied nucleate boiling enhancement by fluid vibrations at $15 \mathrm{~Hz}$ to $100 \mathrm{~Hz}$ and argued that the nucleate boiling region was impossible to enhance. Obinelo et al. [5] studied steam pulsations $(0.08 \mathrm{~Hz}$ to $0.25 \mathrm{~Hz})$ in a reflux condenser and found a several-fold increase in the condensation capacity. Bohdal and Kuczyński [6] investigated pulsating flow in an R134a evaporator coil and found that the superheated region increased with higher cycle times and led to a decrease in the heat transfer performance. Later, the same authors [7] investigated pulsating flow during condensation of R134a in pipe mini-channels ( $0.64 \mathrm{~mm}$ to $3.3 \mathrm{~mm}$ hydraulic diameter) and found that the subcooling area in the condenser increased with increasing cycle time, while the condensation area decreased and led to a decrease of the overall condenser effectiveness. Thus, lowest cycle times (highest pulsating frequencies) performed better for both evaporation and condensation. Chen et al. [8] studied pulsating flow with nearly triangular waves with peakto-peak amplitudes from $10 \%$ to $30 \%$ of the average flow and large cycle times from $30 \mathrm{~s}$ to $120 \mathrm{~s}$. Only a slight impact on the time-averaged heat transfer coefficient and boiling curve was observed at these modest oscillations. Roh and Kim [9] studied flow pulsations in an R410A heat pump and found the coefficient of performance (COP) could be improved by $4 \%$. The authors suggest the enhancement is caused by both the pulsation-enhanced heat transfer and the so-called "pushing effect" that elevated the compressor suction and discharge pressures immediately after each pulse.

Recently, the effect of flow pulsations was studied in an air-to-refrigerant finned-tube evaporator experimentally by Wang et al. [10] using R134a as the refrigerant. The evaporator consisted of 24 staggered tubes, $385 \mathrm{~mm}$ long including U-bends, $6.2 \mathrm{~mm}$ inner diameter, $8.0 \mathrm{~mm}$ outer diameter, 596 fins per meter, and a single refrigerant pass. The pulsations were generated by a solenoid valve, operated at $50 \%$ opening degree and cycle times from $2 \mathrm{~s}$ to $20 \mathrm{~s}$. The results showed that the overall and refrigerant-side heat transfer coefficients improved up to $27 \%$ and 
$123 \%$, respectively, with the highest enhancement at lowest cycle time.

The main objective of the current paper is to demonstrate the possible heat transfer enhancement with flow pulsations by comparing the pulsating flow boiling heat transfer results with that of continuous flow boiling, including the points not addressed in the earlier paper [1] (whole quality range, larger subcooling, four wall temperature measurements, independent heat flux and vapor quality), in order to provide a better foundation for the comparison and analysis, and to consolidate the earlier results. The oscillating dry-out location, superheat and associated system effects are not considered herein. The hypothesis is that the pulsations will increase the flow boiling heat transfer by means of better bulk fluid mixing, increased wall wetting and flow-regime destabilization.

The paper includes a description of the updated experimental apparatus, including the data reduction method and uncertainty analysis, as well as a single-phase heat transfer comparison, and a comparison of the continuous flow boiling results with correlations in the literature. Then the comparison between continuous and pulsating flow boiling is presented in three subsections: a non-normalized presentation of some raw data, a regression-normalized comparison, and some correlation-normalized comparisons. The latter approaches deal in different ways with the challenge that the vapor quality and the heat flux are simultaneous outputs of each experimental run, varying and not directly controllable. Additionally, the flow pulsations are visualized using five glass sections upstream, between and downstream the test sections. Finally, the results are discussed and followed up by the conclusions.

\section{Methods and materials}

\subsection{Experimental apparatus}

The experimental apparatus is illustrated in Figure 1. It consisted of a pump bypass loop from which a small amount of refrigerant (R134a) was circulated through the test sections. The pump bypass loop circulated at least 5 times the refrigerant needed for the test sections. The stepper motor bypass valve controlled the high pressure and the low pressure was controlled by an oversized condenser, and accordingly the temperature of the refrigerated ethylene-glycol/water mixture $(35 / 65 \%)$. The high pressure liquid $\left(T_{\text {sat }}=32{ }^{\circ} \mathrm{C}\right)$ that was extracted from the bypass loop to the 




Figure 1: Experimental apparatus (H: hand-operated valve)

test section was led through a Siemens SITRANS FC300 Coriolis-type mass flow meter with an accuracy of $0.14 \%$ and heated to $12{ }^{\circ} \mathrm{C}$ and $30{ }^{\circ} \mathrm{C}$ by an oversized liquid water heater $(20 \mathrm{~K}$ and 2 $\mathrm{K}$ subcooling). To avoid spurious oscillating mass flow readings, two pulsation dampers were installed both upstream and downstream of the mass flow meter. The subcooled liquid was expanded down to low-pressure two-phase flow $\left(T_{\text {sat }}=5^{\circ} \mathrm{C}\right)$ by exchangeable expansion valves, namely the pulsating flow valve (Danfoss AKV) and the stepper-motor valve (Danfoss ETS). The pulsating flow valve was equipped with a DC coil to minimize time delays associated with AC frequency, and was pulse-width modulated using National Instruments CompactDAQ module 9478. Five 200 $\mathrm{mm}$ long glass tube sections with external vacuum champers were installed upstream, between and downstream of the four test sections to visualize the two-phase flow with a high-speed camera. The first glass section was located $120 \mathrm{~mm}$ downstream of the throat areas of the expansion valves. The remaining liquid was evaporated in an auxiliary evaporator and led back to the pump bypass loop.

The evaporator test sections were identically designed and fabricated. A single test section is sketched in Figure 2 including temperature and pressure sensors. It shows a co-axial type evaporator with refrigerant flowing in the inner tube and distilled water flowing outside helically through three sub-sections, which facilitates the computation of three heat transfer coefficients for each steady state reading per test section (12 in total). Hot water was used instead of electrical heat to evaporate the refrigerant for the following reason: If electrical heaters were used, periodic 


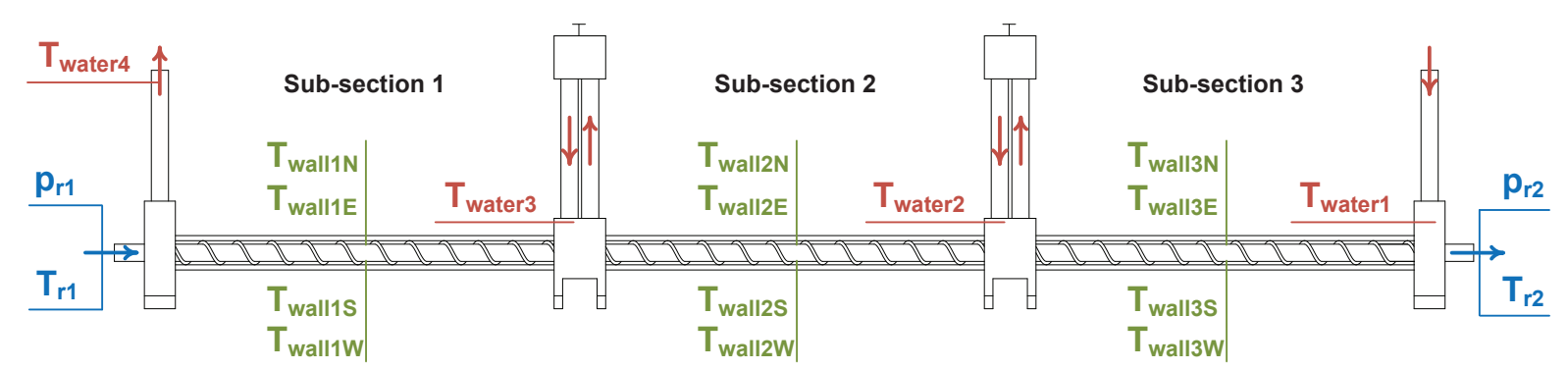

Figure 2: Test section including each sub-section

liquid dry-out at the inner wall surface during flow pulsation would increase the wall temperature rapidly and possibly reach unpractical temperatures compared with typical evaporators, when the pulsating flow valve is closed. On the contrary, the wall temperature would always be limited by the hot water temperature, when hot water is used.

The inner copper tube internal and external diameters were $8 \mathrm{~mm}$ and $10 \mathrm{~mm}$, respectively, and the outer tube inner diameter was $14 \mathrm{~mm}$. The hot water was led away from the annulus through U-bends with air-relief valves or PTFE static mixers to measure a well-mixed average water temperature after each sub-section. The helical flow was arranged by folding a $2 \mathrm{~mm}$ capillary copper tube in a spiral shape before inserting it into the outer transparent acrylic tube during assembly and ensured an even helical angle specified to 30 degrees. The transparent outer tube allowed for a visual inspection of air bubbles before the measurements were recorded. Wall temperatures were measured externally at four locations (north, east, south and west) at the center of each sub-section by soldering $0.5 \mathrm{~mm}$ sheathed thermocouples (Omega Engineering type-T with special limits of error) into $10 \mathrm{~mm}$ grooves along the tube. Special attention was given to avoid any additional thermal capacitance in contact with the inner tube wall in the current design in order to capture the wall temperature oscillation due to flow pulsation. Only small parts in the test section (e.g. o-rings) were allowed to be in contact with the inner tube and all connecting blocks were made of PVC. The capillary tube had a small mass and small contact area with the inner tube too. Pressures and temperatures were measured upstream, between and downstream the test sections. The cold junctions of the thermocouples were installed into an ice-point reference and the hot junction readings were calibrated against a standard resistance thermometer using a calibration bath to an 
accuracy of $0.122 \mathrm{~K}(2 \times$ standard deviation $)$ before installation. The temperature readings were performed by National Instruments CompactDAQ module 9214 configured in high-speed mode and with a sample rate of $10 \mathrm{~Hz}$, in order to resolve the temperature transients due to flow pulsation. The pressure transmitters were also calibrated using a dead-weight tester and resulted in a maximum hysteresis of $200 \mathrm{~Pa}$ and an accuracy of $0.047 \%$ FS (6 bar) and $0.070 \%$ FS (10 bar) for the low and high pressure transmitters, respectively. National Instruments CompactDAQ module 9203 was used to read both refrigerant mass flow and pressure at $1000 \mathrm{~Hz}$. The water flow rates were measured by four oval-gear volume flow meters with accuracies of $(0.48,0.56,0.31$ and $0.58) \%$ FS (1 L/min), respectively and read by National Instruments CompactDAQ module 9411. Experiment monitoring and data logging was made using a developed LabVIEW@ program.

\subsection{Data reduction}

The data reduction was similar to the method used by Wojtan et al. [11]. It is based on a regression of the time-averaged water flow enthalpies, which allows for the computation of the time-averaged local heat flux by differentiation

$$
q(z)=\frac{\rho_{w} \dot{V}_{w}}{\pi d} \frac{d h_{w}}{d z}-q_{\infty}
$$

where $\rho_{w}, h_{w}$, and $\dot{V}_{w}$ are the density, specific enthalpy and volume flow rate of water, $d$ is the inner tube internal diameter and $q_{\infty}$ is the sub-section averaged heat loss or gain through the outer insulation. This value was always calculated to be below $2 \mathrm{~W}$. We found the best regression of the water flow enthalpies by using the following equation:

$$
\frac{h_{w}(z)-b}{h_{w, i n}-b}=\exp (-a(L-z))
$$

which is based on the exact solution of the enthalpy profile in the case of constant wall temperature, properties of water and heat transfer coefficient. The two coefficients $a$ and $b$ are essentially the Number of Transfer Units (NTU) and enthalpy of the water adjacent to the wall, respectively. The regressed values of $a$ and $b$ incorporate the change in wall temperature along the test section and the associated change in the water enthalpy profile. The local heat transfer coefficient was finally computed by 


$$
\frac{1}{\alpha(z)}=\frac{T_{\mathrm{wall}}-T_{\mathrm{sat}}}{q(z)}-\frac{\ln (D / d) d}{2 k}
$$

1 where $T_{\text {sat }}$ is the local saturation temperature evaluated by the measured time-averaged saturation

4 computed by integrating the heat flux

$$
x(z)=x_{\text {in }}+\frac{\pi d}{G A h_{f g}} \int_{0}^{z} q(z) d z
$$

5

where $A, G$ and $h_{f g}$ are the cross-sectional area, refrigerant mass flux and enthalpy of evaporation, respectively. $x_{\text {in }}$ is the inlet vapor quality to the test sections and is computed by the total energy balances surrounding upstream test sections and assuming isenthalpic expansion through the expansion valve. This means that the experimental uncertainty of the reduced vapor quality becomes higher with increasing vapor quality as the energy balances of the upstream test sections were needed for the quality computations in the downstream test sections. This is however not a significant contribution to the experimental uncertainty as will be indicated in the next section.

\subsection{Experimental uncertainty}

Table 1 summarizes the absolute and relative single sample uncertainties using the error propagation method by Kline and McClintock [12] as well as the variable range of the reduced variables from Equation 1, 3 and 4. The absolute uncertainty range from (44 to 241) $\mathrm{W} \mathrm{m}^{-2} \mathrm{~K}^{-1}$ and (124 to 535) $\mathrm{W} \mathrm{m}^{-2}$ for the heat transfer coefficient and heat flux, respectively. Percentagewise, the uncertainty is as much as $17 \%$. These high values occur only at the smallest values of mass flux, heat flux and heat transfer coefficient. On the contrary, $95 \%$ of the data are below $(6.86,7.79$ and 3.1) \% uncertainty for the heat flux, heat transfer coefficient and vapor quality, respectively.

\subsection{Single-phase heat transfer}

Liquid-liquid tests were also conducted in the first test section to ensure the reliability of the measurements and data reduction method. These reduced Nusselt numbers were compared in Figure 3 with the single phase correlation by Gnielinski [13] at Reynolds numbers from 4040 to 
Table 1: Range and uncertainty of reduced variables

\begin{tabular}{lccc}
\hline Variables & Range & Relative uncertainty, \% & Absolute uncertainty \\
\hline Heat flux, $\mathrm{kW} \mathrm{m}^{-2}$ & $1.1-30.6$ & $1.1-17.2$ & $0.124-0.535$ \\
Vapor quality, [-] & $0.06-0.92$ & $0.84-4.72$ & $0.0022-0.0174$ \\
Heat transfer coefficient, $\mathrm{kW} \mathrm{m}^{-2} \mathrm{~K}^{-1}$ & $0.39-5.62$ & $2.3-17.8$ & $0.044-0.241$ \\
\hline
\end{tabular}

1 7700. The comparison resulted in a mean absolute deviation (MAD) and a mean relative deviation 2 (MRD) of (5.1 and 0.17) \%, respectively, where the MAD and MRD are given by

$$
\begin{aligned}
& \text { MAD }=\frac{1}{N} \sum_{i=1}^{N}\left|\frac{\alpha(i)_{\text {pred }}-\alpha(i)_{\exp }}{\alpha(i)_{\exp }}\right| \\
& \text { MRD }=\frac{1}{N} \sum_{i=1}^{N}\left(\frac{\alpha(i)_{\text {pred }}-\alpha(i)_{\exp }}{\alpha(i)_{\exp }}\right)
\end{aligned}
$$

The comparison indicates a good agreement and thus reliable measurements and data reduction method. It should be noticed that the validity of the comparison is restricted to the case of continuous single-phase flow and not pulsating single-phase flow. On the other hand, regarding the two-phase continuous and pulsating flow heat transfer measurements, the energy balances $\left(\dot{Q}_{w}-\dot{Q}_{r}\right)$ were from $-1 \%$ to $-7 \%$, disregarding the lowest mass flux value, thus permitting a fair comparison of the time-averaged continuous and pulsating flow heat transfer. The energy balance is obscured by the low heat flow rates and consequently low temperature difference of the water in the additional evaporator at the lowest mass flux. In this case, the energy balances were from -7 $\%$ to $-11 \%$. The single-phase tests also revealed that the solenoid-driven flow-modulating valve released a nearly constant heat input of $6 \mathrm{~W}$ at $100 \%$ opening degree for all refrigerant flow rates. Ideally, the stepper-motor should not draw any current in a given steady state.

\subsection{Experimental Design}

In the earlier experimental campaign [1], Response Surface Methodology (RSM) was used with the aim of clarifying whether the effect of the flow pulsations is statistically significant. The flow pulsations were found to be statistically significant except at the lowest heat fluxes where 


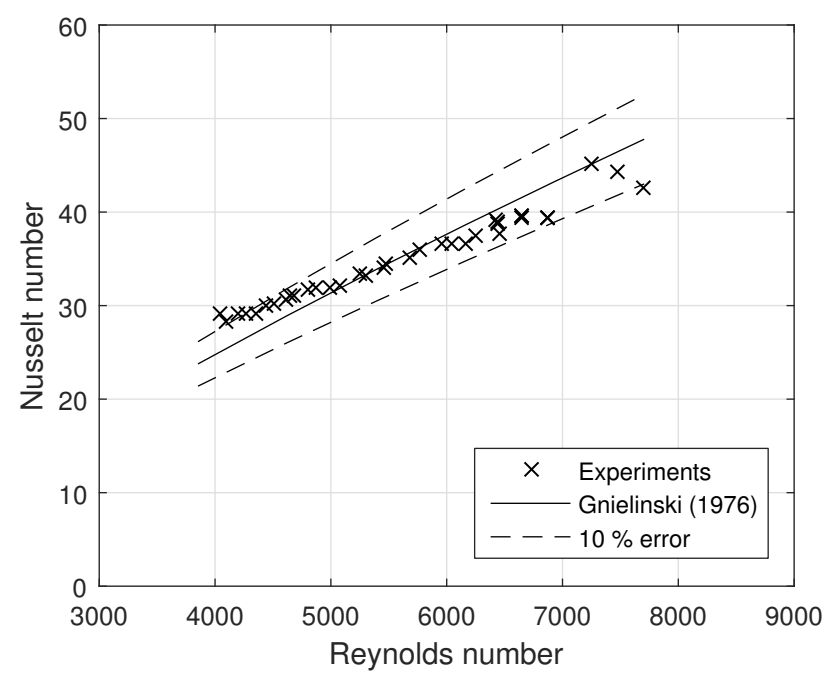

Figure 3: Single-phase liquid Nusselt numbers versus liquid Reynolds number

1 the null hypothesis could not be rejected because of overlapping confidence intervals with that of 2 the continuous flow heat transfer results. The response surfaces were created in terms of mass 3 flux, heat flux and cycle time without the effect of vapor quality, since this parameter was directly 4 dependant on the heat flux in those experiments. Adding an additional factor (vapor quality) to the 5 response surface methodology will increase the confidence intervals of the response, so we chose 6 a more traditional approach for the experimental design, which is introduced in Table 2.

7 The refrigerant mass flux was varied from 50 to $175 \mathrm{~kg} \mathrm{~m}^{-2} \mathrm{~s}^{-1}$ at $2 \mathrm{~K}$ subcooling and from 50 8 to $194 \mathrm{~kg} \mathrm{~m}^{-2} \mathrm{~s}^{-1}$ at $20 \mathrm{~K}$ subcooling. The volume flow of water in each test sections was manually 9 controlled to be similar, such that the time-averaged outlet vapor quality of the fourth test section becomes equal to the dry-out inception quality as proposed by Wojtan et al. [11]

$$
x_{\mathrm{di}}=0.58 \exp \left(0.52-0.235 \mathrm{We}_{g}^{0.17} \mathrm{Fr}_{g}^{0.37}\left(\rho_{g} / \rho_{f}\right)^{0.25}\left(q / q_{\text {crit }}\right)^{0.70}\right)
$$

11 where the critical heat flux is calculated with that of Kutateladze [14]

$$
q_{\text {crit }}=0.131 \rho_{g}^{0.5} h_{f g}\left(g\left(\rho_{f}-\rho_{g}\right) \sigma\right)^{0.25}
$$

The method ensures that the obtained heat transfer results are within most of the quality range without significant transition to dry-out. On the other hand, when comparing the continuous and 
Table 2: Experimental design

\begin{tabular}{lcccc}
\hline Run & $\mathrm{SC}[\mathrm{K}]$ & $G\left[\mathrm{~kg} \mathrm{~m}^{-2} \mathrm{~s}^{-1}\right]$ & $\dot{V}_{w}\left[\mathrm{~m}^{3} \mathrm{~s}^{-1}\right]$ & $x_{\mathrm{di}}[-]$ \\
\hline 1 & 2 & 175 & 0.41 & 0.85 \\
2 & 2 & 50 & 0.13 & 0.94 \\
3 & 2 & 150 & 0.36 & 0.87 \\
4 & 2 & 75 & 0.20 & 0.92 \\
5 & 2 & 100 & 0.25 & 0.90 \\
6 & 2 & 125 & 0.31 & 0.89 \\
7 & 20 & 150 & 0.43 & 0.87 \\
8 & 20 & 50 & 0.16 & 0.94 \\
9 & 20 & 125 & 0.37 & 0.89 \\
10 & 20 & 200 & 0.55 & 0.83 \\
11 & 20 & 175 & 0.49 & 0.85 \\
12 & 20 & 75 & 0.23 & 0.92 \\
13 & 20 & 100 & 0.30 & 0.90 \\
\hline
\end{tabular}

1 the pulsating flow heat transfer, the range of heat flux in each test section changes according 2 to the individual performance, and is adjusted by the manually controlled water volume flow. 3 However, as long as the performances of the continuous and pulsating flow are close, it does 4 provide a comparable range of both vapor qualities and heat fluxes, and no further adjustments in 5 the experimental design methodology was needed. Moreover, transition to dry-out is only allowed 6 periodically in the pulsating flow measurements. If we entered the dry-out or mist flow regime 7 with a sharp decrease in the flow boiling heat transfer coefficient, the gradient of the water enthalpy 8 profile would become non-monotonic and thus it would be difficult to regress and evaluate the local 9 heat flux. Actually, for the lowest mass flux measurements, we had to eliminate some of the heat 10 transfer coefficients obtained in the forth test section, because Equation 2 gave too low coefficient 11 of determination. All other profile regressions resulted in $R_{\text {adj }}^{2}$ values above $98.6 \%$ and on average 99.5\%. In total 152 heat transfer coefficients were obtained for the continous flow according to Table 2. Similarly, 152 heat transfer coefficients were obtained for cycle times $(1,3,5$ and 7$) \mathrm{s}$.

14 In total 608 data points for the pulsating flow were obtained. The saturation temperatures both 
before and after the expansion valves were kept at $32{ }^{\circ} \mathrm{C}$ and $5{ }^{\circ} \mathrm{C}$, respectively. The vapor quality after the expansion valves were consequently 0.18 and 0.05 for the $2 \mathrm{~K}$ and $20 \mathrm{~K}$ subcooling, respectively. The inlet water temperature was also kept constant at $20^{\circ} \mathrm{C}$.

\section{Results}

In this section, firstly the continuous flow measurements are compared with flow boiling correlations in the literature. Secondly, the heat transfer comparison between continuous and pulsating flow boiling is presented. Thirdly, the visualizations with a high-speed camera are presented; these illustrate both pros and cons regarding the pulsations.

\subsection{Continuous flow measurements}

The heat transfer coefficients for the continuous two-phase flow experiments are compared with well-known correlations from the literature in Figure 4 as well as a simple regression that is based on the Boiling number (Bo) and the liquid Weber number $\left(\mathrm{We}_{f}\right)$. This regression was established from a dimensional analysis coupled with multiple regression analysis, and eliminating some non-significant non-dimensional numbers: $\operatorname{Re}_{f}, \operatorname{Re}_{g}, \operatorname{Pr}_{f}, \rho_{g} / \rho_{f}, \mathrm{Bd}$ and $p_{r}$. Some of these do not have significant effect because the saturation temperature is kept at $5{ }^{\circ} \mathrm{C}$ in the experiments, while the effect of others may be included in the $\mathrm{Bo}$ and $\mathrm{We}_{f}$ numbers. The methodology is described in detail in Zhang et al. [15]. The results of the regression may be viewed as a possible obtainable predictability of the results. Figure 4 indicates that the continuous flow heat transfer coefficients are in good agreement with the correlations. Table 3 shows the statistics of the correlations and the regression. It indicates that the correlation by Fang [16] predicts the current results the best with $16.6 \% \mathrm{MAD}$ and $2.5 \% \mathrm{MRD}$, having $80.9 \%$ of the data points within 25 $\%$ deviation, however, it was also specifically developed for R134a in contrast to the other correlations. The regression results in $9.7 \%$ MAD having $96.7 \%$ of the data within $25 \%$ deviation. The phenomenological correlation by Wojtan et al. [11] results in the worst MAD and generally underpredicts the results, which is similar to the correlation by Shah [17]. The correlations by Gungor and Winterton [18] and Jung et al. [19] predict the results slightly better. 

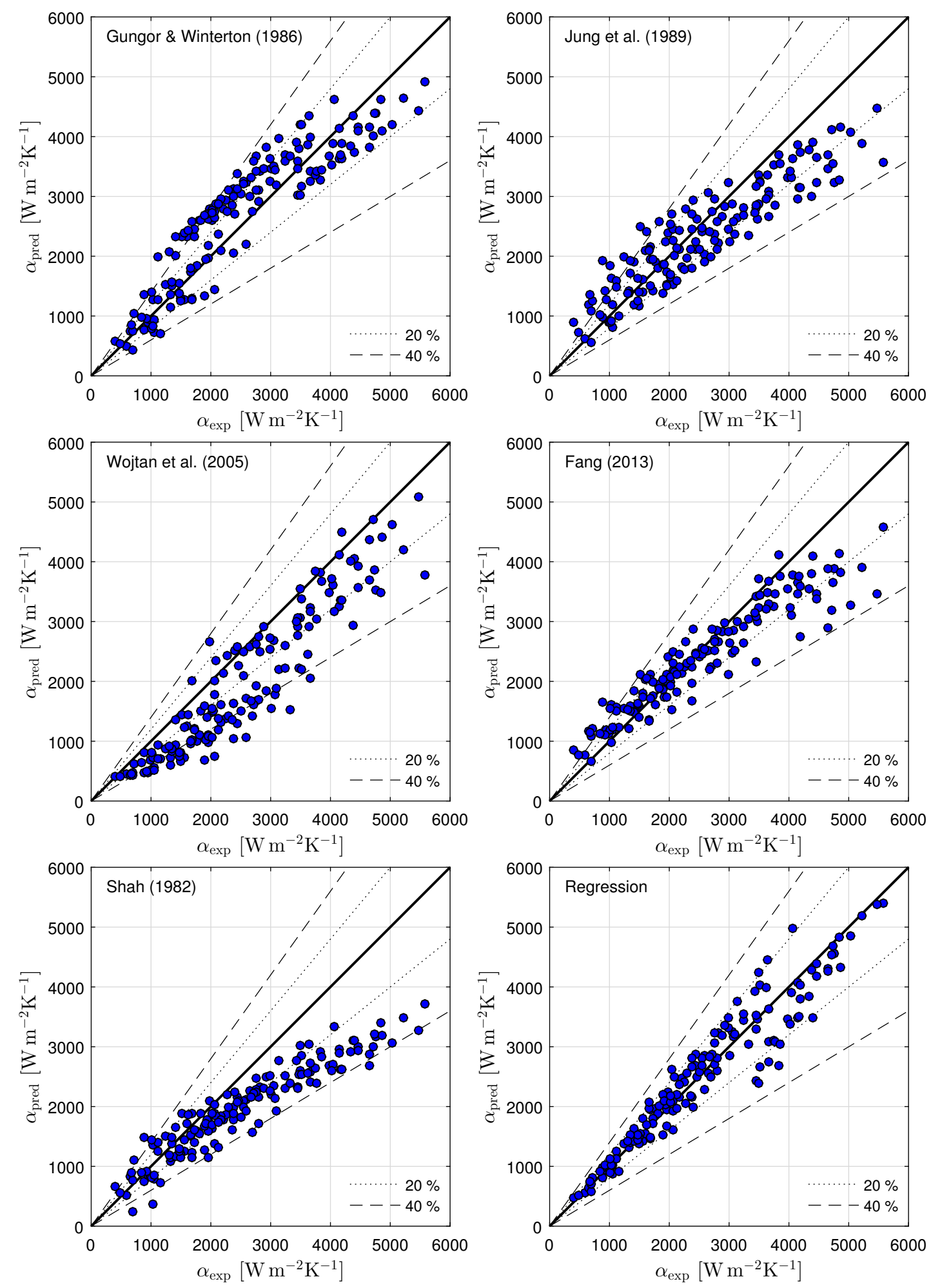

Figure 4: Parity plot of correlated heat transfer coefficients versus the measured heat transfer coefficients for the continuous flow experiments. 
Table 3: Comparison of the continuous flow experiments with well-known flow boiling correlations

\begin{tabular}{|c|c|c|c|c|c|c|}
\hline \multirow[b]{2}{*}{ Correlation } & \multirow[b]{2}{*}{ MAD [\%] } & \multirow[b]{2}{*}{$\operatorname{MRD}[\%]$} & \multicolumn{4}{|c|}{$\begin{array}{l}\text { Percentile of data points within the } \\
\text { given absolute relative deviation [\%] }\end{array}$} \\
\hline & & & $\pm 15 \%$ & $\pm 20 \%$ & $\pm 25 \%$ & $\pm 30 \%$ \\
\hline Gungor and Winterton [18] & 20.8 & 10.9 & 47.4 & 57.2 & 68.4 & 75.7 \\
\hline Shah [17] & 23.3 & -16.5 & 28.3 & 49.3 & 56.6 & 71.1 \\
\hline Jung et al. [19] & 21.8 & 0.5 & 41.4 & 57.9 & 73.0 & 83.6 \\
\hline Wojtan et al. [11] & 26.7 & -25.4 & 30.3 & 39.5 & 46.1 & 52.6 \\
\hline Fang [16] & 16.6 & 2.5 & 57.9 & 72.4 & 80.9 & 86.2 \\
\hline Regression, $54013 \mathrm{Bo}^{0.54} \mathrm{We}_{f}^{0.52}$ & 9.7 & 0.7 & 76.3 & 90.8 & 96.7 & 99.3 \\
\hline
\end{tabular}

\subsection{Heat transfer comparison}

In this section, the local time-averaged heat transfer coefficients are compared directly in all sub-sections of the four test sections. Some of the raw data is presented for both the $2 \mathrm{~K}$ and 20 $\mathrm{K}$ subcooling conditions. However, to account for variations in the typical dependent parameters ( $T_{\text {sat }}, x, q$ and $G$ ) when comparing the continuous and pulsating flow heat transfer coefficients, the entire data set was normalized. This is especially important for the vapor quality and heat flux, since these parameters were not directly controllable and outputs of each experimental run and resulted in slight differences.

\subsubsection{Non-normalized comparison}

Figure 5 shows the continuous and pulsating flow heat transfer coefficients as function of the vapor quality for mass fluxes of (100 and 175) $\mathrm{kg} \mathrm{m}^{-2} \mathrm{~s}^{-1}$ and subcooling of (2 and 20) $\mathrm{K}$. The value of heat flux is indicated by color. It indicates that the changes in the time-averaged heat transfer coefficient with cycle time are small, and also that the differences between the continuous and pulsating flow are small. The heat transfer coefficients for the pulsating flow are higher than for the continuous flow for most cases. This is more apparent at low subcooling. However, it is not always the case. For example, the lowest quality measurements show heat transfer improvements at low subcooling but heat transfer degradations at high subcooling. This observation is visualized 
and discussed in the following section. Furthermore, a low cycle time is generally the best for the pulsating flow measurements, but not always consistent. The effect of heat flux is high at low vapor qualities, which is commonly interpreted as nucleate boiling occurrence, while indicating lower effect at higher vapor qualities. The vapor quality does not seem to have significant effect for the low mass flux, but indicating a moderate increase in heat transfer coefficient at higher mass flux, which is commonly interpreted as more convective boiling occurrence. This may be observed for the values with similar color (same heat flux).

A significant reduction in the heat transfer coefficient is observed for pulsating flow at high vapor qualities and high cycle times for which the pulsating flow causes time-periodic dry-out. Moreover, the liquid film on the wall dries out significantly when the valve is closed and shows a significant degradation in the time-averaged heat transfer coefficient. The reduction is as much as $25 \%$ compared with continuous flow. This observation will also be visualized and discussed in the following section.

\subsubsection{Normalized comparison by regressions}

The normalization of the data was performed using multiple quadratic polynomial regressions, one for each experimental run (value of mass flux and subcooling, according to Table 2). These regressions were only developed using the continuous flow measurements in terms of vapor quality and heat flux, in order to include or normalize the differences in these non-controllable parameters with that of the pulsating flow. These multiple regressions resulted in even better prediction accuracies than the regression in Table 3 and we consider them to be better normalizations than using one of the general correlations. Following this method, both the continuous and pulsating flow data were normalized before the enhancements were calculated. Figure $6 \mathrm{a}$ and $6 \mathrm{c}$ show the normalized heat transfer coefficients as function of the opening time of the pulsating flow expansion valve and with symbols indicating the cycle time. Their ratio results in the opening degree

$$
\mathrm{OD}=\frac{t_{\text {open }}}{t_{\mathrm{cyc}}}
$$

which is close to linearly related with the time-averaged mass flux, thus increasing opening time for the same cycle time means increasing mass flux according to the experimental design. This is 
a

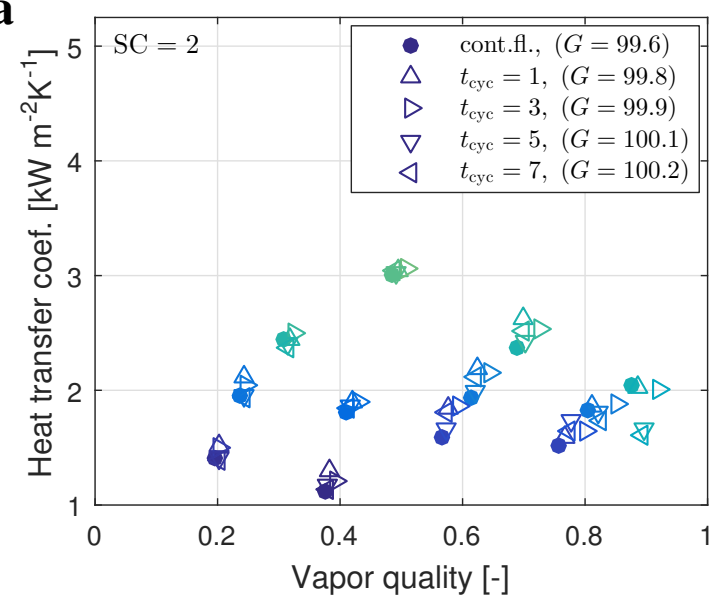

c

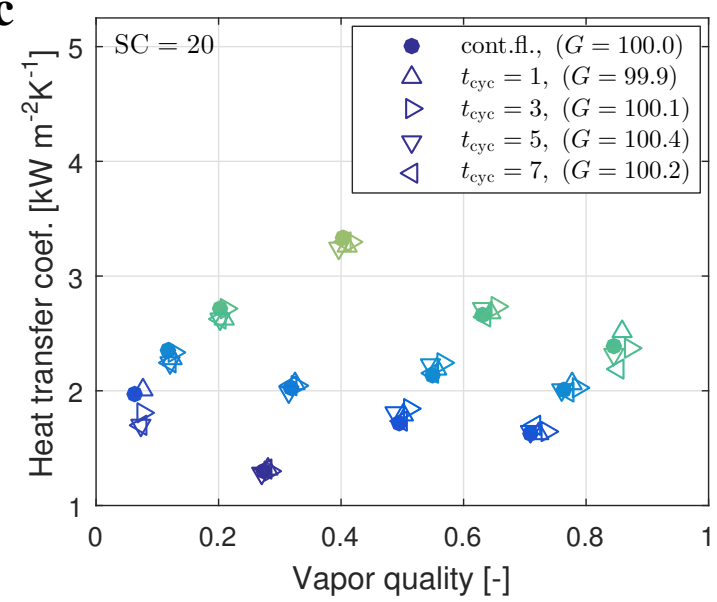

b

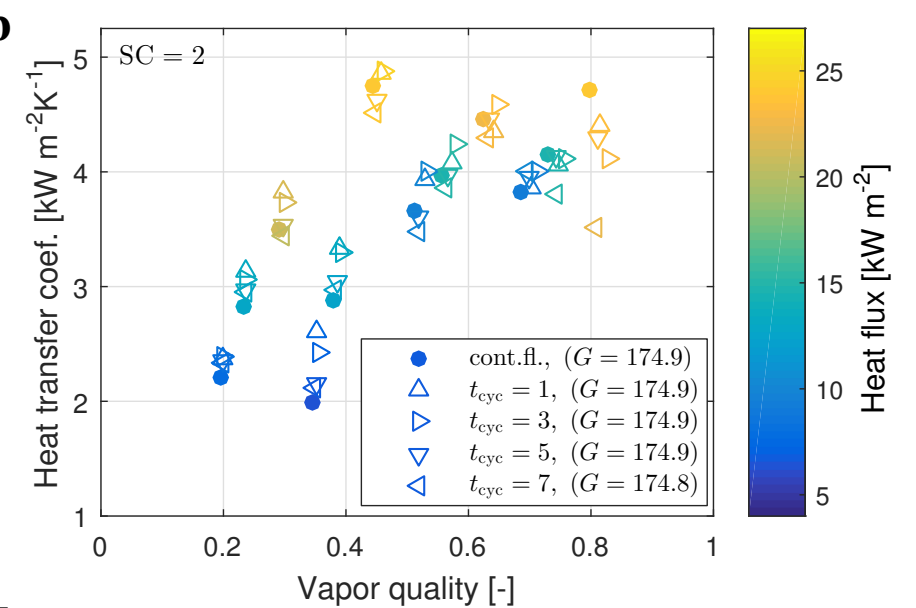

d

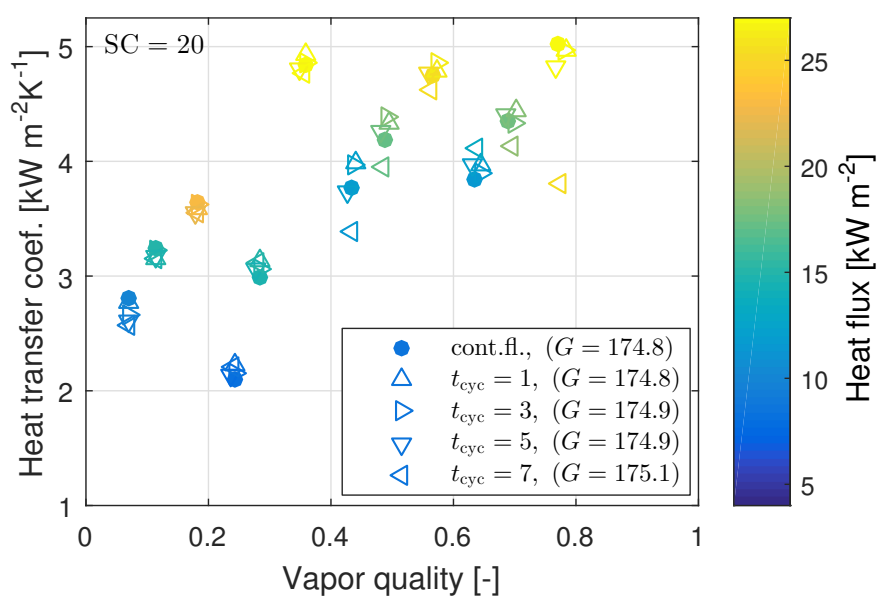

Figure 5: Continuous and pulsating flow heat transfer coefficients at a mass flux of (100 and 175) $\mathrm{kg} \mathrm{m}^{-2} \mathrm{~s}^{-1}$.

1 also indicated in Figure $6 \mathrm{~b}$ and $6 \mathrm{~d}$, which show the average enhancement for all vapor qualities 2 and heat fluxes at each value of mass flux and subcooling.

3 Figure 6 indicates both the variance and the average in the obtained enhancements. Generally, 4 a low opening time and low cycle time result in a significant heat transfer enhancement while a 5 higher opening time and higher cycle time result in no remarkable enhancement. At $7 \mathrm{~s}$ cycle 6 time and high opening time, the result shows a significant decrease in heat transfer due to the 7 aforementioned time-periodic dry-out at the higher time-averaged vapor qualities. Again, the re8 sults indicate that the pulsations lead to higher improvement of the heat transfer coefficients at low 9 subcooling. Due to the variances of the results, it is not always consistent that the pulsating flow 10 performs better at low cycle times, however, the average heat transfer coefficients appear to be 

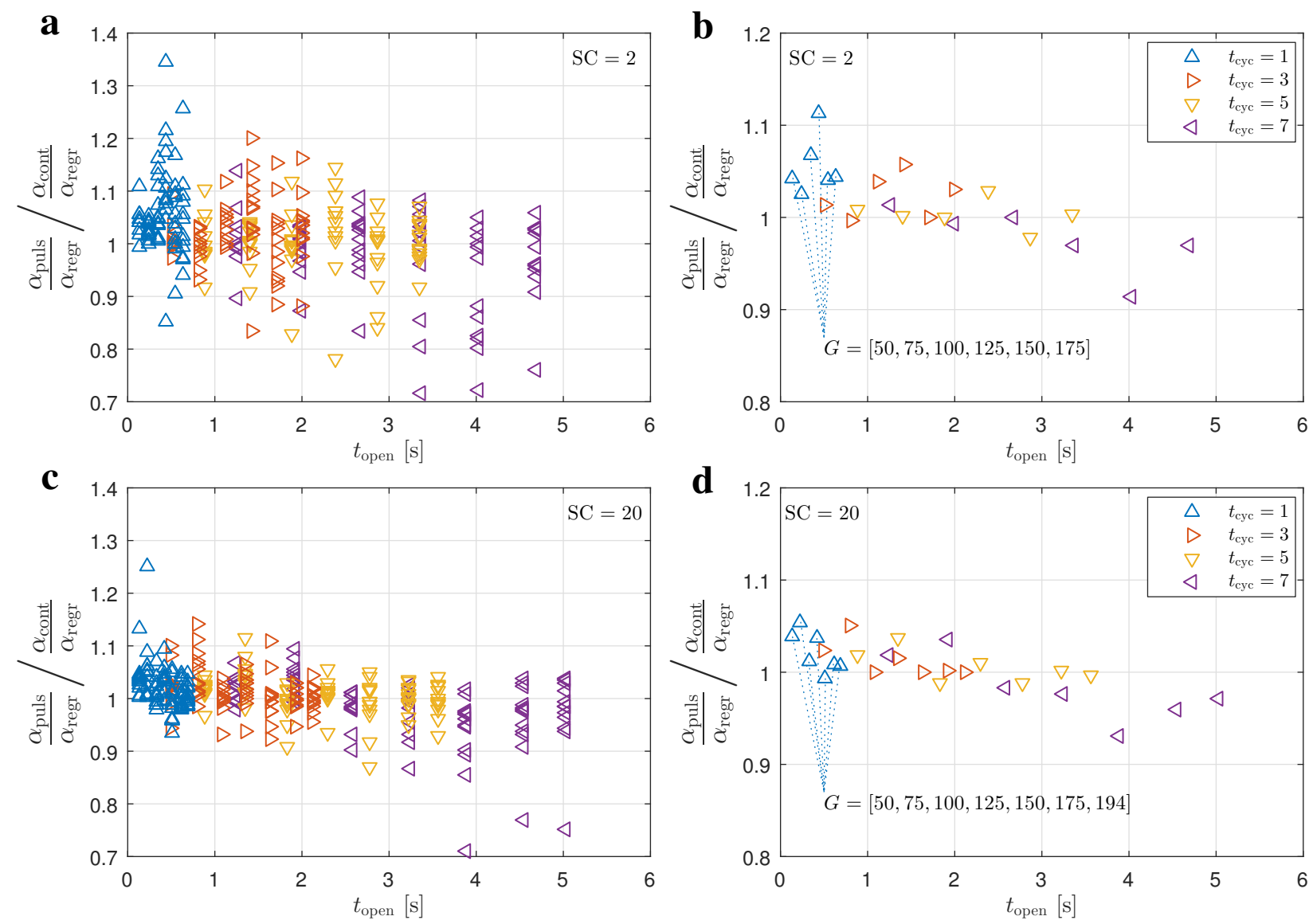

Figure 6: Normalized heat transfer coefficients versus opening time of the pulsating flow expansion valve. $\alpha_{\text {regr }}$ is established from multiple quadratic polynomial regressions of the continuous flow results for each experimental run. (a) and (c) show all individual results, while (b) and (d) show averaged values for each mass flux.

1 higher.

\section{3.2.3. Normalized comparison by correlations}

3 To further analyze the results, several normalizations were conducted using the correlations 4 from Table 3. Table 4 shows the averaged heat transfer enhancement or decrease for all measure5 ments at (2 and 20) K subcooling versus the cycle time. Figure 7 presents the graphical overview

6 for ease of comparison. We also show the non-normalized values and the multiple regression nor7 malized values. The correlation-normalized results are consistently close to each other and follows 8 the same trend, disregarding the normalization by the Fang correlation, which indicate a smaller 9 heat transfer increase with decreasing cycle time. The non-normalized results generally show 
Table 4: Pulsating flow enhancement with and without various normalizations as function of cycle time at $2 \mathrm{~K}$ and 20 K subcooling

\begin{tabular}{|c|c|c|c|c|c|}
\hline \multirow[b]{2}{*}{ Normalization method } & \multirow[b]{2}{*}{ Subcooling $[\mathrm{K}]$} & \multicolumn{4}{|c|}{ Heat transfer enhancement [\%] } \\
\hline & & $t_{\mathrm{cyc}}=1 \mathrm{~s}$ & $t_{\mathrm{cyc}}=3 \mathrm{~s}$ & $t_{\mathrm{cyc}}=5 \mathrm{~s}$ & $t_{\text {cyc }}=7 \mathrm{~s}$ \\
\hline$\alpha_{\text {puls }}$ & 2 & 7.61 & 4.96 & 1.71 & -1.20 \\
\hline$\alpha_{\text {cont }}$ & 20 & 3.22 & 3.30 & 0.78 & -1.09 \\
\hline$\alpha_{\text {puls }} / \alpha_{\text {cont }}$ & 2 & 5.57 & 2.24 & 0.34 & -2.34 \\
\hline$\alpha_{\text {regr }} \overline{\alpha_{\text {regr }}}$ & 20 & 2.16 & 1.32 & 0.55 & -1.79 \\
\hline$\alpha_{\text {puls }} / \alpha_{\text {cont }}$ & 2 & 3.14 & 2.17 & 1.54 & 0.31 \\
\hline$\alpha_{\text {Fang }} / \alpha_{\text {Fang }}$ & 20 & 1.23 & 1.73 & 0.57 & 0.18 \\
\hline$\alpha_{\text {puls }} / \alpha_{\text {cont }}$ & 2 & 5.62 & 2.35 & 0.60 & -2.42 \\
\hline$\alpha_{\text {Jung }} / \alpha_{\text {Jung }}$ & 20 & 1.77 & 1.12 & 0.50 & -1.88 \\
\hline$\alpha_{\text {puls }} / \alpha_{\text {cont }}$ & 2 & 6.13 & 3.12 & 0.81 & -2.16 \\
\hline$\overline{\alpha_{\text {Gung }}} / \overline{\alpha_{\text {Gung }}}$ & 20 & 1.60 & 1.22 & -0.12 & -2.24 \\
\hline$\alpha_{\text {puls }} / \alpha_{\text {cont }}$ & 2 & 6.25 & 3.21 & 1.07 & -1.97 \\
\hline$\alpha_{\text {Shah }} / \alpha_{\text {Shah }}$ & 20 & 1.01 & 0.13 & -0.34 & -2.72 \\
\hline$\alpha_{\text {puls }} / \alpha_{\text {cont }}$ & 2 & 6.35 & 3.39 & 1.06 & -2.13 \\
\hline$\alpha_{\text {Wojt }} / \alpha_{\text {Wojt }}$ & 20 & 2.46 & 2.03 & 0.93 & -1.32 \\
\hline
\end{tabular}

1 higher heat transfer improvements, while the normalization by the Shah correlation shows smaller heat transfer improvement at high subcooling. The multiple regression normalized results agree 3 well with the correlation-normalized results, however showing lower enhancement at low subcool4 ing. In general, lower subcooling shows higher heat transfer enhancement. The enhancement is on 5 average $5.57 \%$ and $2.16 \%$ at $1 \mathrm{~s}$ cycle time for the low and high subcooling, respectively, using 6 the multiple regression normalization. On the other hand, the heat transfer degradation at $7 \mathrm{~s}$ cycle 7 time is around $2 \%$ for both low and high subcooling.

\section{3.3. Visualization}

In this section, the pulsating flow is visualized during the whole cycle and compared with the continuous flow visualization. We include only 10 frames equidistantly distributed throughout 

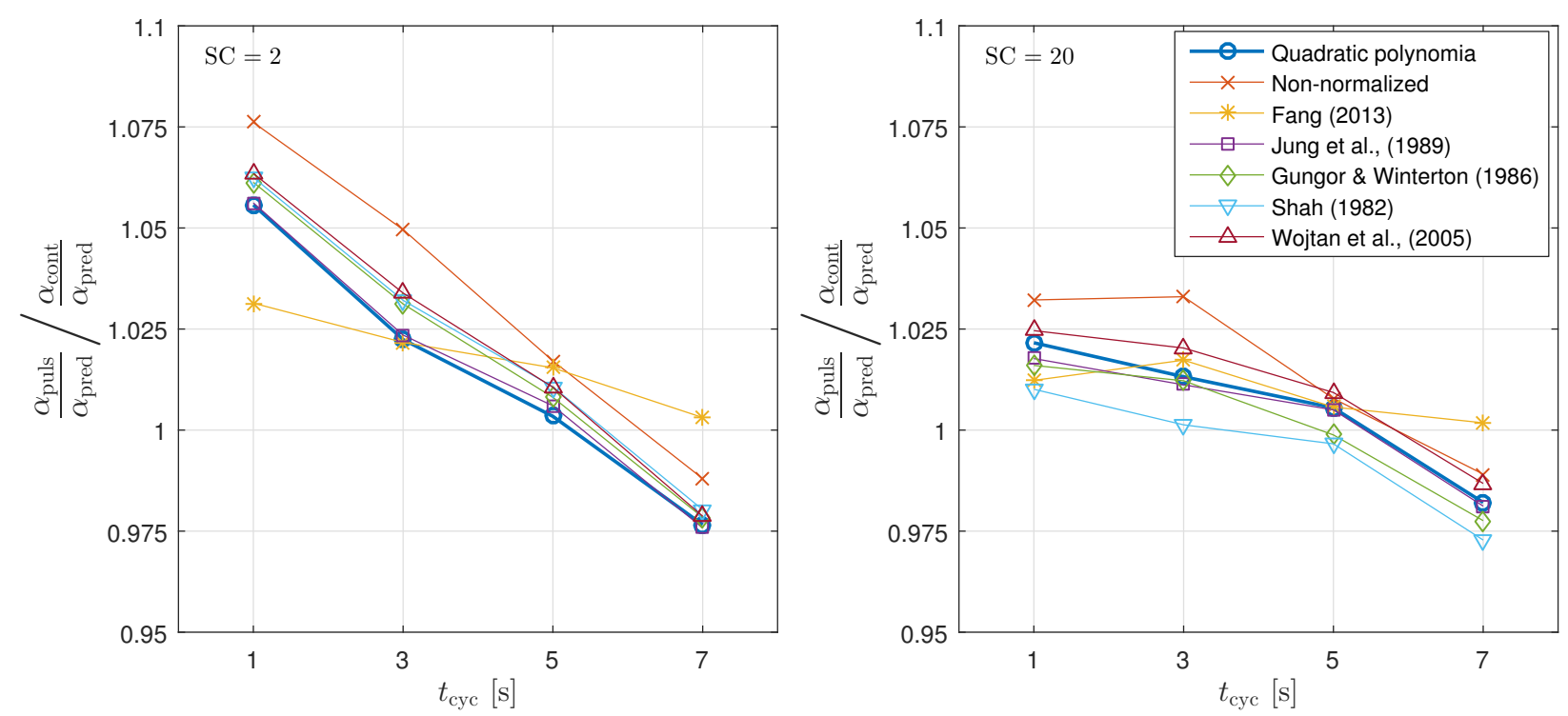

Figure 7: Average heat transfer enhancement versus cycle time.

\subsubsection{Low subcooling}

Figure 8 shows the visualizations at $2 \mathrm{~K}$ subcooling and $5 \mathrm{~s}$ cycle time. The visualization of the continuous flow is placed in the first row of frames, while the rows with time-evolution indicate the pulsating flow with valve opening at $0.00 \mathrm{~s}$. 
The continuous and pulsating flows are inherently different. The continuous flow was rather steady and resulted in two stratified (S) and three stratified-wavy (SW) flow observations. We denote these flow regimes as S and SW depending on the amount and size of waves on the stratified interface. The pulsating flow shows a very stagnant liquid film in the bottom of the tube immediately after the expansion valve (glass section 1$)$ before the valve opens $(0.00 \mathrm{~s})$. In the other locations, S, SW or dry-out (D) occurred due to evaporation of liquid inside the test sections. Visualization of flow regimes is subject to interpretation and further obscured by its inherent stochastic nature and, in the current case, developing flow, which complicates the determination. We denote $\mathrm{D}$ as being a point where liquid is almost non-observable in the bottom of the tube (dry-out completion, transition to mist flow). As the pulsating valve opened ( $0.50 \mathrm{~s}$ to $1.00 \mathrm{~s}$ ), it was interesting to see that Annular (A) flow occurred throughout the glass sections, even immediately after the expansion valve, because it is commonly interpreted as being the best heat transfer flow regime with full wall wetting. We denote the flow regime as annular when a liquid film is wetting the whole tube perimeter, disregarding the distribution of liquid in the top or bottom. The annular flow regime prevailed until the expansion valve closed at around $2.00 \mathrm{~s}$. The stagnation of the liquid film in glass section 1 occurred rather fast, whereas the stratification downstream occurred with a certain time delay (see frames from $1.50 \mathrm{~s}$ to $2.50 \mathrm{~s}$ where the annular flow disappear). As the valve was closed, the liquid in the test sections evaporated and left the evaporator, especially in glass sections 3,4 and 5 . Once the valve opened again (see $0.50 \mathrm{~s}$ ), there was still enough liquid (and gas velocity and interfacial shear) to immediately form annular flow in glass section 4 in contrast to the stratified-wavy flow observed in glass sections 2 and 3. However, dry-out occurred in glass section 5 for at least 2 seconds, essentially prevailed until interruption by the liquid front propagating through the test sections without being evaporated on its way (see glass section 5 at $1.50 \mathrm{~s}$ and $2.00 \mathrm{~s}$ ). This indicates the aforementioned significant time period of dry-out, and is believed to be the main reason that the pulsating flow heat transfer coefficients were found lower at high cycle times (see Figure 5).

Overall, regions were observed with either dry-out or stagnant liquid that may result in lower heat transfer coefficients for the pulsating flow. On the contrary, regions with annular flow were also observed that may result in higher heat transfer coefficients. Referring to Figure $6 \mathrm{~b}$ the aver- 
aged heat transfer coefficients are very similar for this condition $\left(G=100 \mathrm{~kg} \mathrm{~m}^{-2} \mathrm{~s}^{-1}, t_{\mathrm{cyc}}=5 \mathrm{~s}\right)$.

Figure 9 shows the visualizations at $2 \mathrm{~K}$ subcooling and $1 \mathrm{~s}$ cycle time. The continuous flow is repeated in the figure for ease of comparison. It may be noted that the two-phase flow development occurred very fast. After 0.20 seconds, the annular flow regime was observed throughout the glass sections. Similarly, the deceleration occurred fast once the valve closed and resulted in a rather stagnant liquid observed in the first 2 glass sections.

Compared with the $5 \mathrm{~s}$ cycle time visualization (Figure 8), there is no observation of dry-out in glass section 5. In spite of this, the cycles have similar flow regimes throughout their cycles. It is evident that the wall wetting occurred more frequently at low cycle time while avoiding significant dry-out and liquid movement, all leading to increased heat transfer performance at low cycle times. Referring to Figure $6 \mathrm{~b}$ the averaged heat transfer enhancement is $7 \%$ for this condition $\left(G=100 \mathrm{~kg} \mathrm{~m}^{-2} \mathrm{~s}^{-1}, t_{\mathrm{cyc}}=1 \mathrm{~s}\right)$.

\subsubsection{High subcooling}

Figure 10 shows the visualization at $20 \mathrm{~K}$ subcooling and $5 \mathrm{~s}$ cycle time. The vapor quality entering the first glass section was about 0.05 , and it gave rise to near slug formation (note that we could not see directly inside the diabatic test sections, but the first test section might have had strong slugs appearing in it). Moreover, the visual inspection showed strong slugs forming in the first glass section at a time interval of about $10 \mathrm{~s}$ at mass fluxes of (50 and 75) $\mathrm{kg} \mathrm{m}^{-2} \mathrm{~s}^{-1}$. The near slug formation provided a rather dynamic flow which is visualized by 3 different frames to indicate the dynamics in the flow regime of the continuous flow. The pictures are labelled "Cont. flow 1" to "Cont. flow 3" to indicate more activity or liquid in the glass sections. The near slug formations provided a kind of similar behaviour as the pulsating flow, i.e. time-periods with liquid waves travelling forward through the test sections, creating both time-periodic annular and dry-out flow regimes in the fourth and fifth glass section.

Again, the pulsating flow showed a stagnant liquid in the first glass section immediately before the valve opened. As the valve opened, stratified flow occurred in glass section 1 in contrast to the annular flow observed in this glass section at low subcooling. Moreover, stratified and stratifiedwavy flow occurred mostly during the flow pulsation, while annular flow occurred once in glass 
section 3 and mostly in glass section 4. No dry-out was observed in glass section 5. Referring to Figure 6d there is a small decrease in the averaged heat transfer coefficient using flow pulsations for this condition $\left(G=100 \mathrm{~kg} \mathrm{~m}^{-2} \mathrm{~s}^{-1}, t_{\mathrm{cyc}}=5 \mathrm{~s}\right)$.

Figure 11 shows the visualization at $20 \mathrm{~K}$ subcooling and $1 \mathrm{~s}$ cycle time. Again, the continuous flow frames are repeated for ease of comparison. Interestingly, the lower cycle time caused timeperiodic slugs in the first glass section after the valve closed. It was a rather stationary slug that appeared without moving downstream between the frames from $0.50 \mathrm{~s}$ to $0.80 \mathrm{~s}$. The glass sections were adiabatic and did not cause liquid to evaporate and generate a vapor flow that otherwise would move the slug downstream. In contrast, there was a significant liquid flow reversal especially in the top of the tube (see frames at $0.60 \mathrm{~s}$ and $0.70 \mathrm{~s}$ ). Upon $0.80 \mathrm{~s}$, the slug was drawn by the liquid evaporating in test section 1 and further pushed by the valve opening at $1.00 \mathrm{~s}$ as the open/close cycle restarts. The slug seemed to appear in glass section 2 at $0.20 \mathrm{~s}$ in terms of a larger wave and another one in glass section 3 at $0.60 \mathrm{~s}$.

Whether the slug formation enhances heat transfer or causes enhanced heat transfer downstream is difficult to evaluate, however, most of the downstream glass sections indicate that the flow regimes are similar throughout the $5 \mathrm{~s}$ and $1 \mathrm{~s}$ cycles. Compared with the continuous flow, the near slug formation provided a similar effect as the flow pulsations, which may suggest one of the possible reasons for lower heat transfer enhancement at high subcooling. Referring to Figure $6 \mathrm{~d}$ there is a small increase in the averaged heat transfer coefficient using flow pulsations for this condition $\left(G=100 \mathrm{~kg} \mathrm{~m}^{-2} \mathrm{~s}^{-1}, t_{\mathrm{cyc}}=1 \mathrm{~s}\right)$.

\section{Discussion}

Compared with the earlier experimental results [1], the current experimental campaign provides a more complete comparison of the continuous and pulsating flow, targeting the four points raised in Section 1: whole quality range, effect of subcooling, four wall temperatures circumferentially, uncorrelated/independent vapor quality and heat flux. The overall result of the current investigation, was that the low cycle time (1 s) provides a small heat transfer enhancement about $5.6 \%$ and $2.2 \%$ on average at low and high subcooling entering the expansion valves, respectively. This enhancement was a little higher than the $3.2 \%$ found in the preceding study at low 
subcooling [1]. On the other hand, the highest cycle time $(7 \mathrm{~s})$ provided a decrease in the heat transfer coefficient of about $1.8 \%$ and $2.3 \%$ on average for each subcooling. These results were obtained with a single sample uncertainty below $7.8 \%$ for $95 \%$ of all the heat transfer coefficients. The uncertainty was similar to the enhancement, however, with the given amount of data points (152 points for each cycle time value) that were normalized in various ways and averaged, the comparison becomes a reasonable and trustworthy comparison. The overall trend from various normalizations using (1) flow boiling heat transfer correlations in literature, (2) a regression or (3) no normalization is similar, i.e. lower cycle time resulted in higher heat transfer coefficients and vice versa.

The hypothesis that flow pulsations increase flow boiling heat transfer is accepted for low cycle times $(1 \mathrm{~s})$ and low subcooling, even though the enhancement is not great. The hypothesis is rejected for higher cycle times (5-7 s) as well as at high subcooling. The results are attributed to the current test conditions, fluid and design $(8 \mathrm{~mm}$ smooth round tube). Other factors, that may show more or less effect on the enhancement, such as pressure levels before and after the expansion valves, other fluids or mixtures, hydraulic diameters, etc., were not addressed herein. Compared with other flow boiling heat transfer enhancement techniques, flow pulsations does not seem as promising based on the present study. For example, micro-fin tubes with numerous ( 70) low height $(\sim 0.15 \mathrm{~mm})$, spiralling ( $\sim 18 \mathrm{deg})$ fins improve the heat transfer coefficient by as much as $50 \%$ to $100 \%$ [2]; however, the combination with flow pulsations might boost these improvements even more.

Compared with the experimental results obtained by Wang et al. [10], we did not achieve similar dramatic heat transfer enhancements on the order $100 \%$. It is likely that the increased wetting of the inner tube wall was better using a smaller inner tube diameter. Further, the penalty of liquid/vapor stratification is possibly outbalanced in our test-sections by the presence of helical water flow, to alleviate the azimuthal heat conduction through the tube from the top to the bottom. This might increase the continuous flow heat transfer more than that commonly obtained in air-torefrigerant evaporators, for which the azimuthal heat conductions also involves the heat conduction in the fins. On the other hand, our water temperature measurements were quite steady at all considered cycle times. Only refrigerant mass flux, wall temperatures and evaporation pressure 
fluctuated significantly during flow pulsation. However, at the lowest cycle time $(1 \mathrm{~s})$, for which the flow pulsations indicated the best heat transfer, the measured wall temperatures fluctuated less. This indicates that the heat transfer improvement occurs primarily due to the better two-phase flow characteristics (e.g. periodic wetting of the inner tube surface), rather than the periodic heat conduction in the metal or secondary fluid, which seem only to deteriorate the heat transfer.

The visualizations showed that the flow developed quickly upon the opening of the pulsating flow valve at low subcooling due to the higher amount of flash gas with high velocity compared with the high subcooling and lower flash gas generation. This information may be used for other expansion devices such as ejectors for control purposes in $\mathrm{CO}_{2}$ refrigeration systems. Ejectors are difficult to control because they are geometrically complex; however, if the flow develops fast herein and the pressure lift sustains, it may be a valuable ejector control solution. The flow pulsations may also improve refrigerant distribution in multi-circuit evaporators.

\section{Conclusion}

The current paper presents an experimental comparison of flow boiling heat transfer in a waterheated $8 \mathrm{~mm}$ round smooth tube with and without fluid flow pulsation for R134a, i.e. using a flow modulating expansion valve and a stepper motor continuous flow expansion valve. The mass flux ranged from (50 to 194$) \mathrm{kg} \mathrm{m}^{-2} \mathrm{~s}^{-1}$, vapor quality from (0.05 to 0.94) and heat flux from (1.1 to 30.6$) \mathrm{kWm}^{-2}$. For these conditions, it was found that the flow pulsations improve the timeaveraged heat transfer coefficient by $5.6 \%$ and $2.2 \%$ on average at low cycle time $(1 \mathrm{~s})$ and at low and high subcooling before the expansion valve, respectively. However, at high cycle time ( $7 \mathrm{~s})$, the flow pulsations resulted in significant dry-out when the valve was closed, and consequently lower time-averaged heat transfer coefficient, $1.8 \%$ and $2.3 \%$ on average for low and high subcooling, respectively.

Furthermore, the flow pulsations were visualized using a high-speed camera. The visualizations indicated that the flow develops quickly, especially at low subcooling, because of significant flash gas generation during expansion. At high subcooling, the near slug formation in the first glass section provided a dynamic continuous flow with larger liquid waves travelling downstream 
1 and causing intermittent annular flow but also dry-out occurrence. This is a similar flow as the pul-

2 sating flow and is likely one of the reasons that the heat transfer enhancement is lower for higher 3 subcooling.

\section{Acknowledgement}

5 This research was supported by the Danish Council for Independent Research-Technology 6 and Innovation (11-117025).

\section{Nomenclature}

8 Roman

9 A cross-sectional area, $\mathrm{m}^{2}$

Bo boiling number $\left[q /\left(h_{f g} g\right)\right]$

11

Bd Bond number $\left[\left(\rho_{f}-\rho_{g}\right) g d^{2} / \sigma\right]$

${ }_{12} \quad c_{p}$ specific heat capacity, $\mathrm{J} \mathrm{kg}^{-1} \mathrm{~K}^{-1}$

13 $D$ outer tube diameter, $\mathrm{m}$

${ }_{14} d$ inner tube diameter, $\mathrm{m}$

$15 \operatorname{Fr}_{g}$ vapor Froude number based on Mori et al. [20] $\left[G^{2} /\left(\rho_{g}\left(\rho_{f}-\rho_{g}\right) g d\right)\right]$

${ }_{16} G$ mass flux, $\mathrm{kg} \mathrm{m}^{-2} \mathrm{~s}^{-1}$

$17 g$ gravitational acceleration, $\mathrm{m} \mathrm{s}^{-2}$

${ }_{18} h$ specific enthalpy, $\mathrm{J} \mathrm{kg}^{-1}$

${ }_{19} \quad k$ thermal conductivity, $\mathrm{W} \mathrm{m}^{-1} \mathrm{~K}^{-1}$

${ }_{20} L$ test section length, $\mathrm{m}$

${ }_{21} p_{r}$ reduced pressure, -

$22 \operatorname{Pr}_{f}$ liquid Prandtl number $\left[c_{p f} \mu_{f} / k_{f}\right]$

23 $q$ heat flux, $\mathrm{W} \mathrm{m}^{-2}$

${ }_{24} \dot{Q}$ heat flow rate, $\mathrm{W}$

${ }_{25} R_{\text {adj }}$ adjusted coefficient of determination, -

${ }_{26} \operatorname{Re}_{f}$ liquid Reynolds number $\left[G(1-x) d / \mu_{f}\right]$ 
$1 \operatorname{Re}_{g}$ vapor Reynolds number $\left[G x d / \mu_{g}\right]$

$2 \quad T$ temperature, ${ }^{\circ} \mathrm{C}$

$3 \quad t_{\text {cyc }}$ cycle time, $\mathrm{s}$

$4 t_{\text {open }}$ opening time, $\mathrm{s}$

${ }_{5} \dot{V}$ volume flow rate, $\mathrm{m}^{3} \mathrm{~s}^{-1}$

${ }_{6} \quad \mathrm{We}_{f}$ liquid Weber number $\left[G^{2} d /\left(\rho_{f} \sigma\right)\right]$

$7 \mathrm{We}_{g}$ vapor Weber number $\left[G^{2} d /\left(\rho_{g} \sigma\right)\right]$

$8 x$ vapor quality, -

$9 \quad x_{\mathrm{de}}$ dry-out completion quality, -

$10 x_{\mathrm{di}}$ dry-out inception quality, -

$11 \quad z$ axial coordinate, $\mathrm{m}$

12 Greek

${ }_{13} \alpha$ heat transfer coefficient, $\mathrm{W} \mathrm{m}^{-2} \mathrm{~K}^{-1}$

${ }_{14} \mu$ dynamic viscosity, $\mathrm{N} \mathrm{s} \mathrm{m}^{-2}$

$15 \rho$ density, $\mathrm{kg} \mathrm{m}^{-3}$

${ }_{16} \sigma$ surface tension, $\mathrm{N} \mathrm{m}^{-1}$

17 Subscripts

18 cont continuous

19 crit critical

20 exp experimental

${ }_{21} f$ liquid

$22 g$ vapor

23 pred predicted

24 puls pulsation

${ }_{25} r$ refrigerant

26 sat saturation

$27 \quad w$ water

28 wall wall

${ }_{29} \infty$ ambient 
1 Abbreviations

2 MAD mean average deviation

3 MRD mean relative deviation

4 OD valve opening degree

5 SC subcooling

\section{References}

7 [1] M. R. Kærn, B. Elmegaard, K. E. Meyer, B. Palm, J. Holst, Continuous versus pulsating flow boiling. Experimental comparison, visualization, and statistical analysis, Science and Technology for the Built Environment (2017) 1-14ISSN 2374-4731, doi:10.1080/23744731.2017.1319667, URL https://www. tandfonline.com/doi/full/10.1080/23744731.2017.1319667.

[2] A. E. Bergles, High-flux processes through enhanced heat transfer, in: Rohsenow symposium on future trends in heat transfer, Massachusetts, USA, 2003.

[3] M. M. Ohadi, S. V. Dessiatoun, J. Darabi, M. Salehi, Active Augmentation of Single-Phase and Phase-Change Heat Transfer - an overview, in: R. M. Manglik, A. D. Kraus (Eds.), Process, Enhanced, and Multiphase Heat Transfer, Begell House, New York, USA, 277-286, 1996.

[4] V. A. Antonenko, Y. G. Chistyakov, G. R. Kudritskiy, Vibration-aided boiling heat transfer, Heat Transfer Research 24 (8) (1992) 1147 - 1151, ISSN 21626561.

[5] I. F. Obinelo, G. F. Round, J. S. Chang, Condensation enhancement by steam pulsation in a reflux condenser, International Journal of Heat and Fluid Flow 15 (1) (1994) 20-29, ISSN 0142727X, doi:10.1016/0142-727X(94)90027-2.

[6] T. Bohdal, W. Kuczyński, Investigation of Boiling of Refrigeration Medium Under Periodic Disturbance Conditions, Experimental Heat Transfer 18 (3) (2005) 135-151, ISSN 0891-6152, doi:10.1080/08916150590953379.

[7] W. Kuczyski, H. Charun, T. Bohdal, Influence of hydrodynamic instability on the heat transfer coefficient during condensation of R134a and R404A refrigerants in pipe mini-channels, International Journal of Heat and Mass Transfer 55 (4) (2012) 1083-1094, ISSN 00179310, doi:10.1016/j.ijheatmasstransfer.2011.10.002.

[8] C. Chen, W. Chang, T. Lin, Time periodic flow boiling heat transfer of R-134a and associated bubble characteristics in a narrow annular duct due to flow rate oscillation, International Journal of Heat and Mass Transfer 53 (19-20) (2010) 3593-3606, ISSN 00179310, doi:10.1016/j.ijheatmasstransfer.2010.02.038.

[9] C. W. Roh, M. S. Kim, Enhancement of heat pump performance by pulsation of refrigerant flow using a solenoid-driven control valve, International Journal of Refrigeration 35 (6) (2012) 1547-1557, ISSN 01407007 , doi:10.1016/j.ijrefrig.2012.04.018. 
[10] X. Wang, K. Tang, P. S. Hrnjak, Evaporator performance enhancement by pulsation width modulation (PWM), Applied Thermal Engineering 99 (2016) 825-833, doi:10.1016/j.applthermaleng.2015.12.049, URL http://dx.doi.org/10.1016/j.applthermaleng.2015.12.049.

[11] L. Wojtan, T. Ursenbacher, J. R. Thome, Investigation of flow boiling in horizontal tubes: Part II—Development of a new heat transfer model for stratified-wavy, dryout and mist flow regimes, International Journal of Heat and Mass Transfer 48 (14) (2005) 2970-2985, ISSN 00179310, doi:10.1016/j.ijheatmasstransfer.2004.12.013.

[12] S. Kline, F. McClintock, Describing uncertainties in Single-Sample experiments, Mechanical Engineering 75 (1) (1953) 3-8, ISSN 00256501.

[13] V. Gnielinski, New equation for heat and mass transfer in turbulent pipe and channel flow, International Chemical Engineering 16 (1976) 359-368.

[14] S. Kutateladze, On the transition to film boiling under natural convection, Kotloturbostroenie 3 (8) (1948) 10-12.

[15] J. Zhang, A. Desideri, M. R. Kærn, T. S. Ommen, J. Wronski, F. Haglind, Flow boiling heat transfer and pressure drop characteristics of R134a, R1234yf and R1234ze in a plate heat exchanger for organic Rankine cycle units, International Journal of Heat and Mass Transfer 108 (2017) 1787-1801, ISSN 00179310, doi:10.1016/j.ijheatmasstransfer.2017.01.026, URL http://linkinghub.elsevier.com/retrieve/pii/S0017931016335025.

[16] X. Fang, A new correlation of flow boiling heat transfer coefficients based on R134a data, International Journal of Heat and Mass Transfer 66 (2013) 279-283, ISSN 00179310, doi:10.1016/j.ijheatmasstransfer.2013.07.015.

[17] M. M. Shah, Chart correlation for saturated boiling heat transfer: Equations and further study, ASHRAE Transactions 88 (1982) 185-196.

[18] K. E. Gungor, R. H. S. Winterton, A general correlation for flow boiling in tubes and annuli, International Journal of Heat and Mass Transfer 29 (1986) 351-358, doi:10.1016/0017-9310(86)90205-X.

[19] D. Jung, M. McLinden, R. Radermacher, D. Didion, A study of flow boiling heat transfer with refrigerant mixtures, International Journal of Heat and Mass Transfer 32 (9) (1989) 1751-1764, doi:10.1016/0017-9310(89)90057-4.

[20] H. Mori, S. Yoshida, K. Ohishi, Y. Kakimoto, Dryout quality and post-dryout heat transfer coefficient in horizontal evaporator tubes, in: 3rd European thermal sciences conference, 839-844, 2000. 

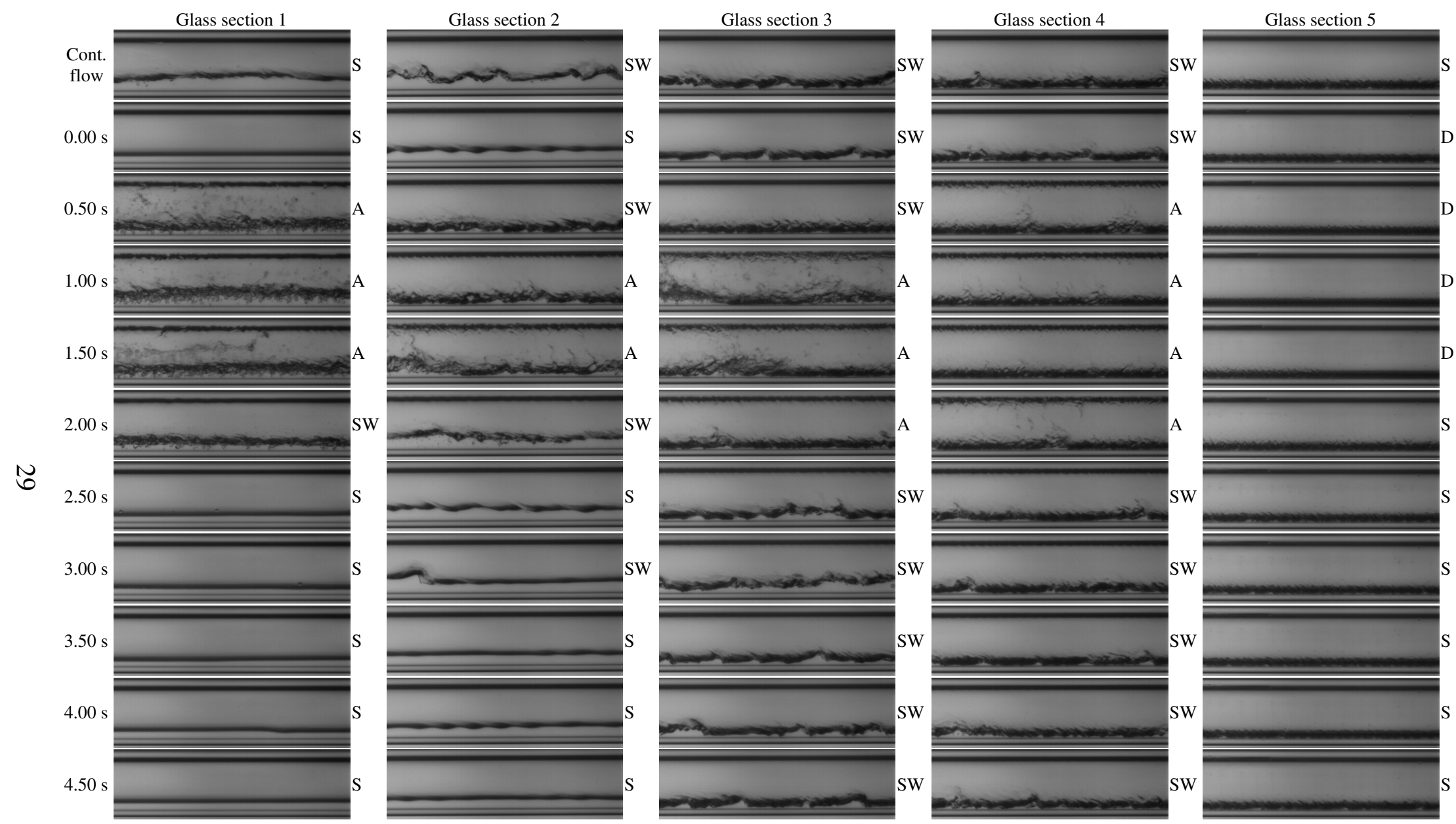

Figure 8: Visualization of the continuous and pulsating flow $\left(t_{\mathrm{cyc}}=5 \mathrm{~s}, \mathrm{SC}=2 \mathrm{~K}, \mathrm{G}=100 \mathrm{~kg} \mathrm{~m}^{-2} \mathrm{~s}^{-1}\right)$, see "Video 1 Continuous flow SC2 G100.mp4" and "Video 2 Pulsating flow SC2 G100 Cyc5.mp4". 

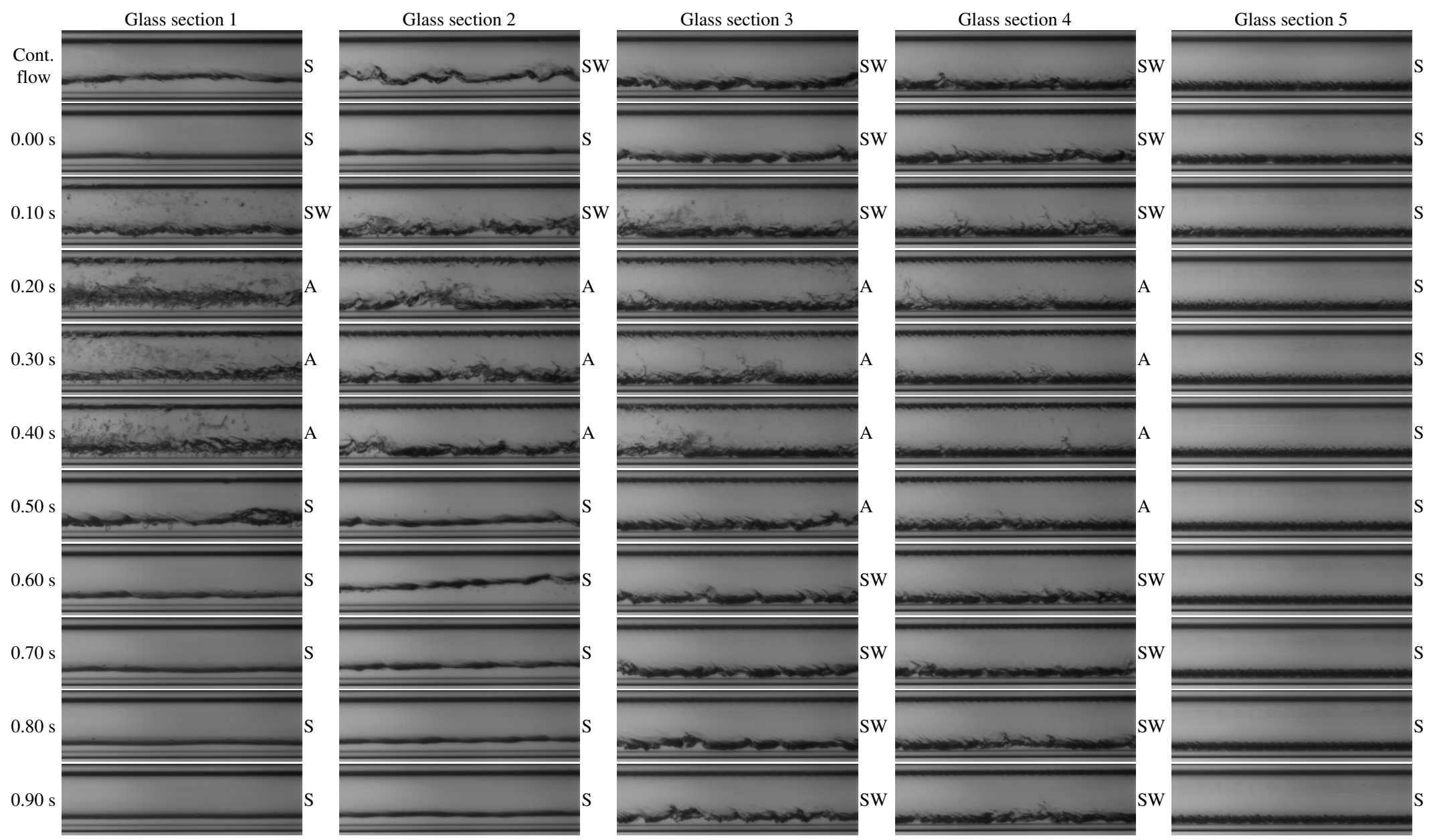

Figure 9: Visualization of the continuous and pulsating flow $\left(t_{\mathrm{cyc}}=1 \mathrm{~s}, \mathrm{SC}=2 \mathrm{~K}, \mathrm{G}=100 \mathrm{~kg} \mathrm{~m}^{-2} \mathrm{~s}^{-1}\right)$, see "Video 1 Continuous flow SC2 G100.mp4" and "Video 3 Pulsating flow SC2 G100 Cyc1.mp4". 


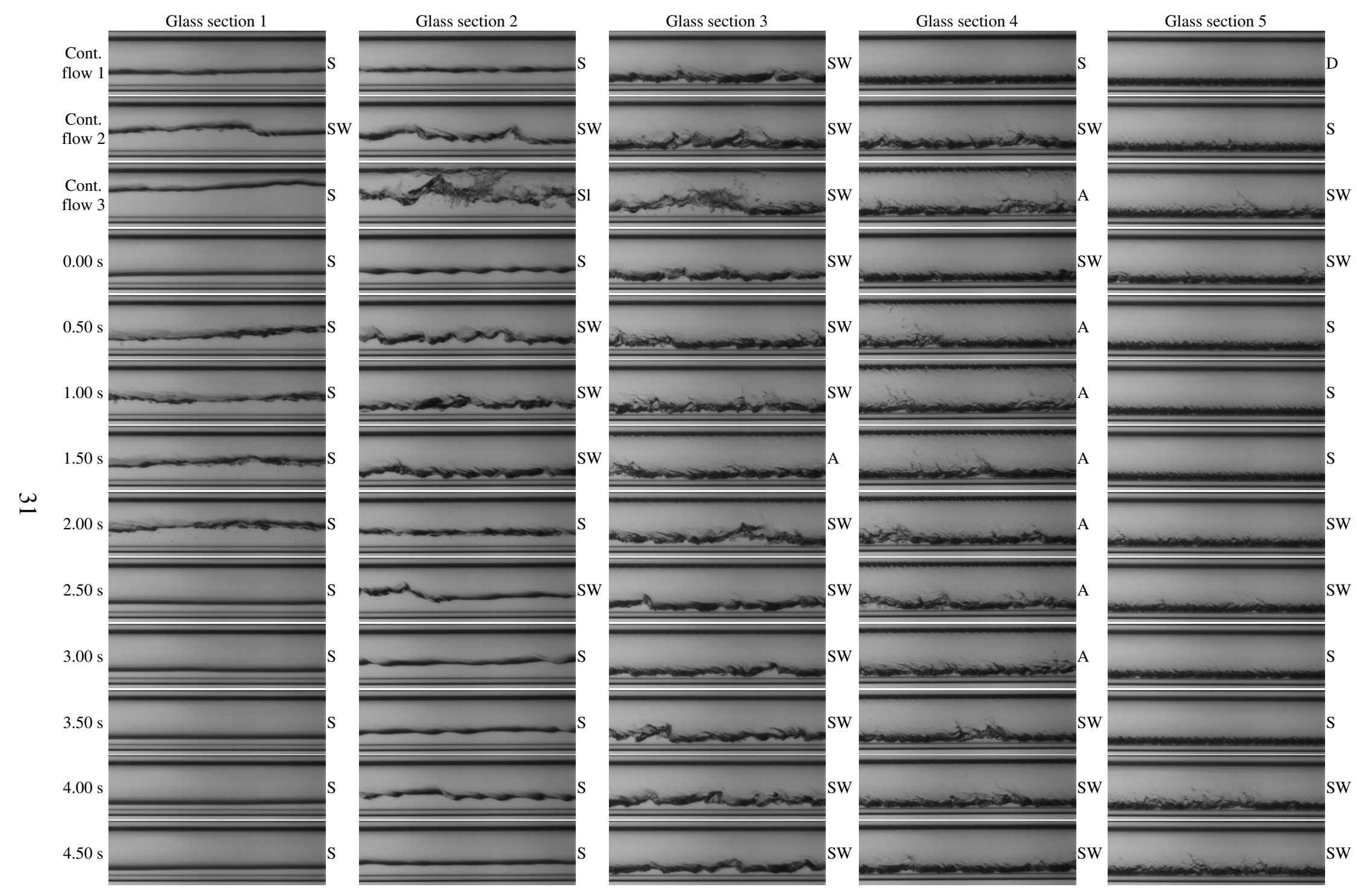

Figure 10: Visualization of the continuous and pulsating flow ( $t_{\mathrm{cyc}}=5 \mathrm{~s}, \mathrm{SC}=20 \mathrm{~K}, \mathrm{G}=100 \mathrm{~kg} \mathrm{~m}^{-2} \mathrm{~s}^{-1}$ ), see "Video 4 Continuous flow SC20 G100.mp4" and "Video 5 Pulsating flow SC20 G100 Cyc5.mp4". 

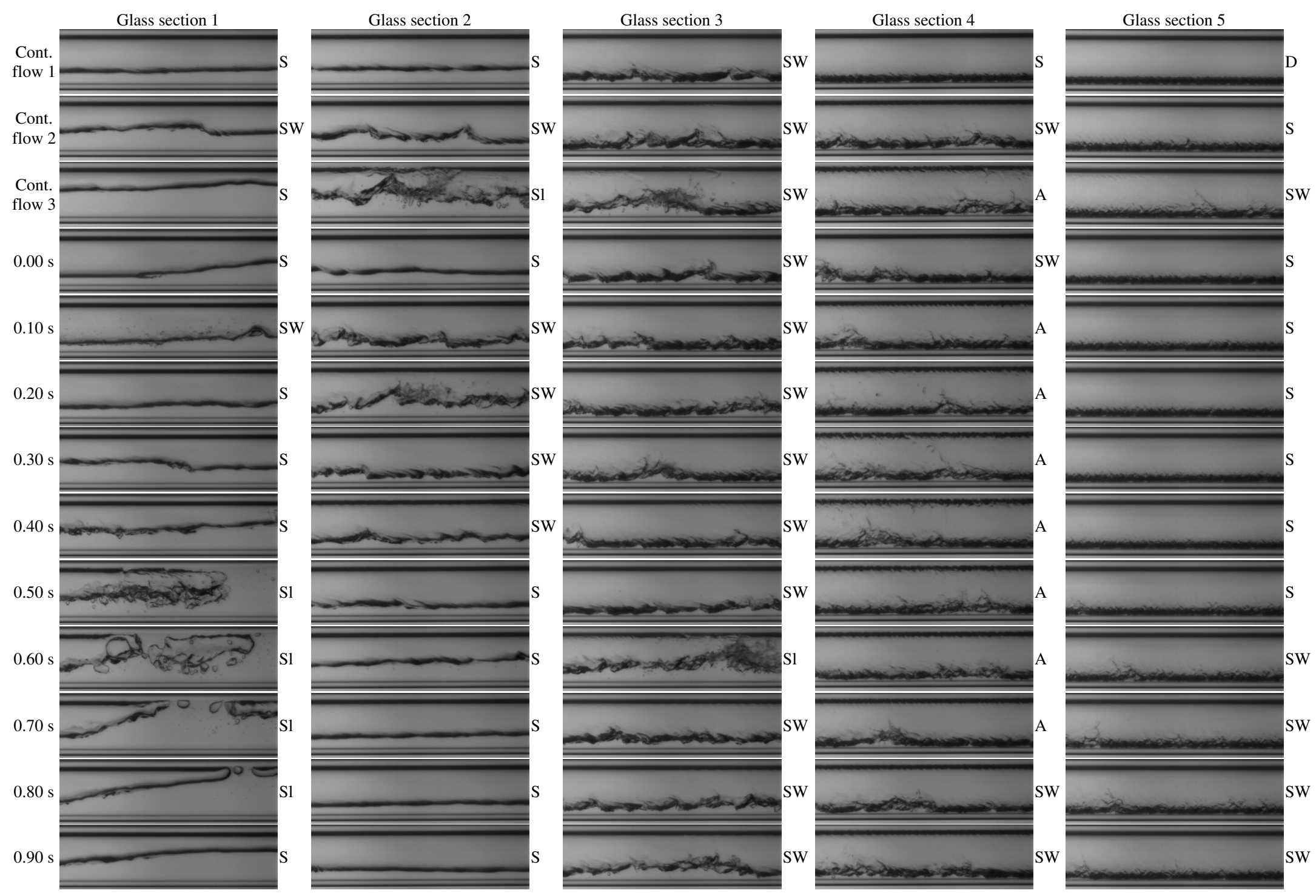

Figure 11: Visualization of the continuous and pulsating flow ( $t_{\mathrm{cyc}}=1 \mathrm{~s}, \mathrm{SC}=20 \mathrm{~K}, \mathrm{G}=100 \mathrm{~kg} \mathrm{~m}^{-2} \mathrm{~s}^{-1}$ ), see "Video 4 Continuous flow SC20 G100.mp4" and "Video 6 Pulsating flow SC20 G100 Cyc1.mp4". 